\title{
PENGARUH KEPEMIMPINAN TRANSFORMASIONAL, MOTIVASI DAN BUDAYA KERJA TERHADAP KINERJA PEGAWAI BADAN PENYELENGGARA JAMINAN SOSIAL (BPJS) KESEHATAN CABANG LANGSA
}

\author{
Surya Darma \\ Universitas Islam Sumatera Utara \\ surya.darma@gmail.com
}

\begin{abstract}
In an increasingly complex and ever-changing business environment, the study of leadership can no longer be as simple as using these two dimensions. Likewise, efforts to find the best leadership style that applies throughout time will be in vain. There is a need to find a leadership model that is more relevant to complex situations like today. Transformational leadership is one of the "breakthrough" concepts that has revived the passion of leadership studies that have almost died over the past decade. Motivation can also be interpreted as providing a driving force that creates the excitement of one's work to be willing to work together, work effectively and be integrated with all their efforts to achieve satisfaction. From the results of the identification of the problems above, the problem can be formulated as follows: How is the influence of Transformational Leadership on the Performance of BPJS Health Officers in Langsa Branch. As for the Results of this Research Performance = 24,007 C +, $195 X 1+, 016 X 2+, 214 X 3$ explanation can be described as follows: Constant value of 24.007 means that if the overall value of the variable (SinismeX1, Emotional IntelligenceX2, Work StressX3) rises by 1 a respectively, the Performance value (Y) will rise to 24.007. Cynic coefficient value of 0.195 means that if the value of Cynicism increases by 1 a, the performance value will also increase by 0.195. Positive coefficient value means that Cynicism has a positive influence on performance. The value of the Emotional Intelligence coefficient of 0.016 means that if the value of Emotional Intelligence rises by 1 , the performance value will also increase by 0.016. A positive coefficient value means that Emotional Intelligence has a positive influence on Performance. The value of the Job Stress coefficient of 0.214 means that if the value of Job Stress rises by $1 a$, the performance value will also increase by 0.214. A positive coefficient value gives the meaning that Job Stress gives a positive influence on Performance.
\end{abstract}

Keywords: Transformational Leadership, Motivation, Work Culture

ABSTRAK : Dalam lingkungan bisnis yang semakin kompleks dan selalu berubah seperti saat ini, studi kepemimpinan tidak bisa lagi sesederhana penggunaan dua dimensi tersebut. Demikian pula upaya pencarian gaya kepemimpinan terbaik yang berlaku sepanjang masa akan sia-sia. Ada kebutuhan untuk menemukan model kepemimpinan yang lebih relevan dengan situasi kompleks seperti sekarang ini. Kepemimpinan transformasional merupakan salah satu konsep "terobosan" yang berhasil menghidupkan kembali gairah studi kepemimpinan yang hampir mati selama dekade terakhir ini. Motivasi juga dapat diartikan pemberian daya penggerak yang menciptakan kegairahan kerja seseorang agar mau bekerjasama, bekerja efektif dan terintegrasi dengan segala daya upayanya untuk mencapai kepuasan. Dari hasil identifikasi masalah di 
atas, dapat dirumuskan masalah sebagai berikut :Bagaimana pengaruh Kepemimpinan Transformasional terhadap Kinerja Pegawai BPJS Kesehatan Cabang Langsa. Adapun Hasil Penelitian ini Kinerja $=24,007 C+, 195 X^{1}+, 016 X^{2}+, 214 X^{3}$ Berdasarkan hasil persamaan tersebut maka dapat diuraikan penjelasan sebagai berikut : Nilai Konstanta sebesar 24,007 memberikan arti bahwa jika secara keseluruhan nilai variable (SinismeX ${ }^{1}$, Kecerdasan EmosionalX ${ }^{2}$, Stres KerjaX ${ }^{3}$ ) naik masing sebesar $1_{a}$ maka nilai Kinerja $(Y)$ akan naik menjadi 24,007. Nilai koefisien Sinisme sebesar 0,195 memberikan arti bahwa jika nilai Sinisme naik sebesar $1_{a}$ maka nilai kinerja juga akan naik sebesar 0,195. Nilai koefisienyang positif memberikan arti bahwa Sinisme memberikan pengaruh positif terhadap Kinerja. Nilai koefisien Kecerdasan Emosional sebesar 0,016 memberikan arti bahwa jika nilai Kecerdasan Emosional naik sebesar $1_{a}$ maka nilai kinerja juga akan naik sebesar 0,016. Nilai koefisien yang positif memberikan arti bahwa Kecerdasan Emosional memberikan pengaruh positif terhadap Kinerja.Nilai koefisien Stres Kerja sebesar 0,214 memberikan arti bahwa jika nilai Stres Kerja naik sebesar $1_{a}$ maka nilai kinerja juga akan naik sebesar 0,214. Nilai koefisien yang positif memberikan arti bahwa Stres Kerja memberikan pengaruh positif terhadap Kinerja.

\section{Kata Kunci : Kepemimpinan Transformasional, Motivasi, Budaya Kerja}

\section{Pendahuluan}

Dalam lingkungan bisnis yang semakin kompleks dan selalu berubah seperti saat ini, studi kepemimpinan tidak bisa lagi sesederhana penggunaan dua dimensi tersebut. Demikian pula upaya pencarian gaya kepemimpinan terbaik yang berlaku sepanjang masa akan sia-sia. Ada kebutuhan untuk menemukan model kepemimpinan yang lebih relevan dengan situasi kompleks seperti sekarang ini. Kepemimpinan transformasional merupakan salah satu konsep "terobosan" yang berhasil menghidupkan kembali gairah studi kepemimpinan yang hampir mati selama dekade terakhir ini. Menurut konsep ini, tugas seorang pemimpin adalah berupaya memotivasi bawahannya agar dapat berprestasi melampaui harapan dan perkiraan sebelumnya. Esensi kepemimpinan adalah memfasilitasi pengembangan individu untuk merealisasi potensi dirinya.

Tulisan ini mernbahas kepemimpinan transformasional dan pemberdayaan karyawan. Pembahasan diawali dengan menelusuri secara sekilas berbagai teori kepemimpinan; kemudian, dilanjutkan dengan telaah terhadap mitos gaya kepemimpinan "terbaik". Selanjutnya ulasan difokuskan pada berbagai karakteristik kepemimpinar transformasional yang merupakan trend kepemimpinan di masa datang. Akhirnya, tulisan ini mengupas pandangan mengenai pentingnya dimensi pemberdayaan (empowerment) dalam kepemimpinan manajerial, terutama untuk menyongsong era transformasi akibat perubaha lingkungan yang terjadi secara dramatik.Sumber daya manusia penting karena berperan untuk menggerakkan sumber daya lainnya untuk mencapai tujuan organisasi.

Di dalam pengelolahan SDM, apabila individu dalam organisasi yaitu sumber daya manusianya dapat berjalan efektif maka organisasi tetap berjalan efektif. Beberapa kegiatan pengelolahan SDM misalnya pengadaan, penilaian, perlindungan, memotivasi pegawai, memberdayakan pegawai, peningkatan disiplin, bimbingan, dll. Pengelolaan dan pengoptimalan sumber daya manusia tidak lepas dari faktor pegawai. Organisasi harus mempunyai pegawai mempunyai kinerja yang baik. Dengan kata lain kelangsungan suatu organisasi ditentukan oleh kinerja pegawainya (Robertus 2016;26).

Dalam pengelolaan sumber daya manusia terdapat kepemimpinan, yang menjadi tonggak 
awal sebuah organisasi akan di bawa kearah mana. Kepemimpinan merupakan dimana orang memberi pengaruh besar untuk menggerakkan setiap lingkuangannya (organisasi) untuk mencapai tujuan. Kepemimpinan yang baik akan memberi target dalam setiap kebijakan, namun selalu memberi buah yang mampu menjadi pemicu yaitu dengan menghargai setiap prestasi kerja yang ada , memberikan seluas-luasnya pengembangan karir teradap pegawai, seingga setiap kerja keras yang dilakukan pegawai akan selalu diperatikan, tidak luput juga memberikan lingkungan kerja yang baik dan kondusif bagi pegawai agar tetap nyaman saat bekerja. Sehingga banyaknya target yang mesti di raih jika diimbangi dengan hal-hal tersebut bisa memulikan kembali kinerja pegawai.

Motivasi adalah karakteristik psikologi manusia yang memberi kontribusi pada tingkat komitmen seseorang. Motivasi termasuk factor-faktor yang menyebabkan, menyalurkan, dan mempertahankan tingkah laku manusia dalam arah tekad tertentu (Almustofa,2014: 74)

Motivasi juga dapat diartikan pemberian daya penggerak yang menciptakan kegairahan kerja seseorang agar mau bekerjasama, bekerja efektif dan terintegrasi dengan segala daya upayanya untuk mencapai kepuasan.

Pada dasarnya perusahaan bukan saja mengharapkan karyawan yang mampu, cakap, dan terampil, tetapi yang terpenting mereka mau bekerja giat dan berkeinginan untuk mencapai hasil kerja yang optimal. Motivasi penting karena dengan motivasi ini diharapkan setiap individu karyawan mau bekerja keras dan antusias untuk mencapai kinerja yang tinggi.

Pokok permasalahannya adalah dimana pegawai sudah kehilangan semangat kerja, sehingga kepemimpinan transformasional yang diterapkan tidak membawa pengaruh positif pada budaya kerja yang hendak diterapkan. Pegawai kehilangan motivasi, pekerjaan banyak yang tidak terselesaikan, pelayanan tidak maksimal seperti yang diharapkan yang mengakibatkan kinerja pegawai semakin buruk.

Penelitian ini bertujuan untuk mengetahui dan menganalisis:

a. Pengaruh Kepemimpinan Transformasional terhadap Kinerja Pegawai BPJS Kesehatan Cabang Langsa

b. Pengaruh Motivasi terhadap Kinerja Pegawai BPJS Kesehatan Cabang Langsa.

c. Pengaruh Budaya Kerja terhadap Kinerja Pegawai BPJS Kesehatan Cabang Langsa.

d. Pengaruh Kepemimpinan

Transformasional, Motivasi dan Budaya kerja terhadap Kinerja Pegawai BPJS Kesehatan Cabang Langsa.

\section{Metode Penelitian}

\subsection{Lokasi Penelitian}

Lokasi penelitian akan dilakukan di Jalan Prof. A Majid Ibrahim (Sei Paluh) No.5 Langsa 29912. Badan Penyelenggara Jaminan Sosial (BPJS) Kesehatan Cabang Langsa.

\subsection{Populasi}

Menurut (Sevilla,2007:82), populasi adalah wilayah generalisasi yang terdiri atas obyek/subjek yang mempunyai kuantitas dan karakteristik tertentu yang ditetapkan oleh peneliti untuk dipelajari dan kemudian ditarik kesimpulannya. Dari pengertian tersebut, maka dapat disimpulkan bahwa populasi merupakan subjek penelitian dimana individu yang akan dikenai perilaku atau dapat dikatakan sebagai keseluruhan objek penelitian yang akan diteliti. Berdasarkan data pegawai secara keseluruhan di Badan Penyelenggara Jaminan Sosial (BPJS) Kesehatan Cabang Langsa yang berjumlah 47 orang

\subsection{Sampel}

Sampel adalah elemen-elemen populasi yang dipilih atas dasar kemampuan 
mewakilinya. Menurut (Sevilla,2007:85), untuk menjadi pedoman maka apabila subjeknya kurang dari 100, lebih baik diambil semua sehingga penelitiannya merupakan penelitian populasi. Selanjutnya jika jumlah subjeknya besar dapat diambil antara 10-15\% atau 20-25\% atau lebih. (Sinungan,2001:37) mengatakan bahwa sampel merupakan bagian yang diambil dari populasi. Dengan teknik penarikan sampel secara total sampling atau metode sensus, maka sampel dalam penelitian ini berjumlah 47 orang yang terdiri pada bidang - bidang yang dianggap peneliti mempunyai konteribusi langsung pada variable yang di teliti.

\subsection{Definisi Operasional Variabel}

Variabel yang digunakan dalam penelitian ini terdiri dari : a. Variabel Bebas (Independent Variable) dengan simbol $\mathrm{X}$, yaitu terdiri dari kepemimpinan transformasional, motivasi dan budaya kerja pegawai BPJS Kesehatan Cabang Langsa.

b. Variabel Terikat (Dependent Variable) dengan simbol Y, yaitu kinerja pegawai BPJS Kesehatan Cabang Langsa.

\subsection{Teknik Analisis Data}

Teknik analisis data dalam penelitian ini meliputi: Analisis Deskriptif, Uji Kualitas Data, pengujian Hipotesis, dan Koefisien determinasi.

\section{Analisi dan Pembahasan}

\subsection{Analisi Regresi Berganda}

Adapun hasil regresi linear berganda dalam penelitian ini dapat dilihat pada tabel berikut ini:

Tabel 1

Hasil Regresi Linear Berganda

Coefficients $^{\mathrm{a}}$

\begin{tabular}{|c|r|r|r|r|r|r|r|}
\hline \multirow{2}{*}{ Variable } & \multicolumn{2}{|c|}{$\begin{array}{c}\text { Unstandardized } \\
\text { Coefficients }\end{array}$} & $\begin{array}{c}\text { Standardized } \\
\text { Coefficients }\end{array}$ & \multirow{2}{*}{$\mathrm{t}$} & \multirow{2}{*}{ Sig. } & \multicolumn{2}{|c|}{$\begin{array}{c}\text { Collinearity } \\
\text { Statistics }\end{array}$} \\
\cline { 2 - 4 } \cline { 7 - 8 } & \multicolumn{1}{|c|}{ B } & Std. Error & \multicolumn{1}{c|}{ Beta } & & & Tolerance & VIF \\
\hline (Constant) & 24,007 & 16,015 & & 2,499 &, 014 & & \\
\hline$X^{1}$ &, 195 &, 339 &, 090 &, 575 &, 047 &, 904 & 1,107 \\
\hline$X^{2}$ &, 016 &, 178 &, 014 &, 089 &, 030 &, 918 & 1,090 \\
\hline$X^{3}$ &, 214 &, 174 &, 184 &, 226 &, 027 &, 984 & 1,017 \\
\hline
\end{tabular}

Sumber data diolah dengan SPSS 24, 2019

Berdasarkan hasil regresi linear berganda pada tabel diatas maka dapat dibuat persamaan sebagai berikut :

$$
\text { Kinerja }=\underset{, 214 X^{3}}{24,007 ~} \mathrm{C}+, 195 \mathrm{X}^{1}+, 016 \mathrm{X}^{2}+
$$

Berdasarkan hasil persamaan tersebut maka dapat diuraikan penjelasan sebagai berikut :

a. Nilai Konstanta sebesar 24,007

memberikan arti bahwa jika secara keseluruhan nilai variable (Kepemimpinan TransformasionalX ${ }^{1}$, Motivasi $X^{2}$, Budaya Kerja $X^{3}$ ) naik masing sebesar $1_{a}$ maka nilai Kinerja (Y) akan naik menjadi 24,007. b. Nilai koefisien

Kepemimpinan Transformasional sebesar 0,195 memberikan arti bahwa jika nilai Kepemimpinan Transformasional naik sebesar $1_{\mathrm{a}}$ maka nilai kinerja juga akan naik sebesar 0,195 . Nilai koefisienyang positif memberikan arti bahwa Kepemimpinan Transformasional memberikan pengaruh positif terhadap Kinerja.

c. Nilai koefisien Motivasi sebesar 0,016 memberikan arti bahwa jika nilai Motivasi naik sebesar $1_{\mathrm{a}}$ maka nilai kinerja juga akan naik sebesar 0,016 . Nilai koefisien yang 
positif memberikan arti bahwa Motivasi memberikan pengaruh positif terhadap Kinerja.

d. Nilai koefisien Budaya Kerja sebesar 0,214 memberikan arti bahwa jika nilai Budaya Kerja naik sebesar $1_{\mathrm{a}}$ maka nilai kinerja juga akan naik sebesar 0,214. Nilai koefisien yang positif memberikan arti

bahwa Budaya Kerja memberikan pengaruh positif terhadap Kinerja.

\subsection{Uji Hipotesa}

\subsubsection{Uji Parsial (Uji t)}

Uji parsial (Uji t) dilakukan untuk menjawab pertanyaan yang telah diajukan baik pada identifikasi, rumusan masalah maupun hipotesis penelitian secara parsial atau individu.

Tabel 2

Uji Parsial (Uji t)

\begin{tabular}{|l|l|l|l|l|l|}
\hline \multirow{2}{*}{ Variable } & \multicolumn{2}{|l|}{$\begin{array}{l}\text { Unstandardized } \\
\text { Coefficients }\end{array}$} & $\begin{array}{l}\text { Standardized } \\
\text { Coefficients }\end{array}$ & \multirow{2}{*}{$\mathrm{t}$} & \multirow{2}{*}{ Sig. } \\
\cline { 2 - 4 } & $\mathrm{B}$ & Std. Error & Beta & & \\
\hline (Constant) & 24,007 & 16,015 & & 2,499 &, 014 \\
\hline $\mathrm{X}^{1}$ &, 195 &, 339 &, 090 &, 575 &, 047 \\
\hline $\mathrm{X}^{2}$ &, 016 &, 178 &, 014 &, 089 &, 030 \\
\hline $\mathrm{X}^{3}$ &, 214 &, 174 &, 184 &, 226 &, 027 \\
\hline
\end{tabular}

Sumber data diolah dengan SPSS 24, 2019

Berdasarkan hasil pengujian Signifikansi parsial (Uji-t) pada tabel diatas dapat dilihat bahwa nilai probabilitas < Nilai Alpha sebesar 0,05 maka hipotesis diterima dan sebaliknya. Apabila nilai Sig. Probabilitas > nilai alpha sebesar 0,05 maka hipotesis ditolak.

Tabel 2 diketahui bahwa nilai signifikansi dari Kepemimpinan Transformasional $\left(\mathrm{X}_{1}\right)$ adalah 0.047 nilai ini lebih kecil dari nilai alphanya yang sebesar 0.05 . Dengan demikian dapat dinyatakan bahwa Pengaruh Kepemimpinan Transformational berpengaruh positif dan berpengaruh signifikan terhadap Kinerja Pegawai, Selanjutnya diketahui bahwa nilai signifikansi dari Motivasi $\left(\mathrm{X}_{2}\right)$ adalah 0.030 nilai ini lebih kecil dari nilai alphanya yang sebesar 0.05. Dengan demikian dapat dinyatakan bahwa Motivasi memiliki pengaruh positif dan signifikan terhadap
Kinerja pegawai. Selanjutnya di ketahui bahwa nilai signifikansi Budaya Kerja $\left(\mathrm{X}_{3}\right)$ adalah 0,027 nilai ini lebih kecil dari 0,05 dengan demikian Budaya Kerja memiliki pengaruh positif dan signifikan terhadap Kinerja pegawai di BPJS Kesehatan Cabang Langsa. . Hal ini dapat kita ketahui walaupun Kepemimpinan Transformasional, Motivasi dan Budaya Kerja berpengaruh positif dan signifikan terhadap kinerja pegawai di BPJS Kesehatan Cabang Langsa.

\subsubsection{Uji Simultan (Uji F)}

Uji serempak dilakukan untuk melihat tingkat signifikansi variabel bebas secara bersama - sama berpengaruh terhadap variabel terikat. Hasil uji secara serempak dapat dilihat pada tabel dibawah ini : 
Tabel 3

Uji F

ANOVA $^{\mathrm{a}}$

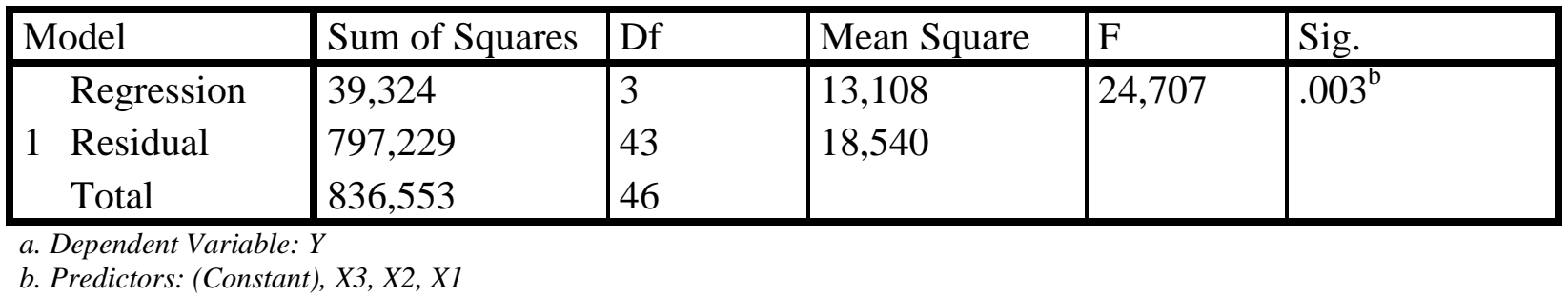

Tabel 3 menunjukkan bahwa nilai Kinerja Pegawai di BPJS Kesehatan Cabang signifikansi adalah sebesar 0.003. Nilai Langsa.

signifikansi tersebut lebih kecil dibandingkan dengan nilai Alpha sebesar 0.05. Sehingga dapat disimpulkan bahwa secara bersama sama Pengaruh Kepemimpinan Transformasional, Motivasi dan Budaya Kerja Di BPJS Kesehatan Cabang Langsaberpengaruh signifikan terhadap

\subsubsection{Koefisien Determinasi $\left(\mathbf{R}^{2}\right)$}

Untuk dapat mengetahui besarnya Pengaruh Kepemimpinan Transformasional, Motivasi dan Budaya Kerja dalam menjelaskan Kinerja Pegawai dapat dilihat pada koefisien determinasinya yang berada pada tabel 5.16 berikut :

Tabel 4

Koefisien Determinasi

Model Summary

\begin{tabular}{|l|l|l|l|l|}
\hline Model & $\mathrm{R}$ & $\mathrm{R}$ Square & Adjusted R Square & Std. Error of the Estimate \\
\hline 1 & $.517^{\mathrm{a}}$ & .470 &, 019 & 4,30583 \\
\hline
\end{tabular}

a. Predictors: (Constant), X3, X2, X1

b. Dependent Variable $y$

Berdasarkan pada tabel 4 diketahui bahwa nilai R-Square adalah sebesar 0,517. Artinya bahwa Kepemimpinan Transformasional, Motivasi dan Budaya Kerja mampu menjelaskan Kinerja Pegawai adalah sebesar $51,7 \%$ sisanya $48,3 \%$ dijelaskan oleh variabel lain yang tidak dimasukkan ke dalam model penelitian ini.

\section{Kesimpulan}

Penelitian ini dimaksudkan untuk mengetahui pengaruh Kepemimpinan Transformasional, Motivasi dan Budaya Kerja terhadap kinerja pegawai BPJS Kesehatan Cabang Langsa. Berdasarkan hasil penelitian dan pembahasan maka dapat ditarik kesimpulan dari penelitian adalah : a. Kepemimpinan Transformasional berpengaruh secara positif dan signifikan terhadap kinerja pegawai di BPJS Kesehatan Cabang Langsa.

b. Motivasi berpengaruh secara positif dan signifikan terhadap kinerja pegawai di BPJS Kesehatan Cabang Langsa.

c. Budaya kerja berpengaruh secara positif dan signifikan terhadap kinerja pegawai di BPJS Kesehatan Cabang Langsa.

\section{DAFTAR PUSTAKA}

Adlina Setiani (2014), Kualiatas Kehidupan Kerja Terhadap Kinerja Dengan Komitmen 
Organisasi Intervening Variabel, e-Journal adbisnis Fisip Unmul.ac.id

Almustofa (2014) "Pengaruh Dukungan, Organisasi dan Motivasi Terhadap Kinerja pegawai”. (Studi pada pegawai Perum Bulog Divisi Regional Jakarta), Universitas Sebelas Maret.

Andy Pradana, Martha.2013. Pengaruh gaya kepemimpinan Transformasional dan Transaksional terhadap terhadap Kinerja Karyawan; Studi kasus pada karyawan tetap PT. Mustika Bahana Jaya, Lumajang : Universitas Brawijaya.

Brass, B.M. (2008), "Does the transactionaltransformational leadership paradigm transcend organisational and national boundaries", American Psychologist, Vol. 52 No.2, pp.130-9.

Buchori Zainun. 2014. Manajemen dan Motivasi. Balai Aksara, Jakarta.

Danim, Sudarman.2013. Motivasi Kepemimpinan dan Efektivitas kelompok. Jakarta : Rineka Cipta Utama.

Dessler, Garry (2008), Manajemen Sumber Daya Manusia, PT. Preshelindo, Jakarta.

Djoko Widagdho, Ilmu Budaya Dasar, Cetakan Kesembilan, (Jakarta: PT. Bumi Aksara, 2009)

Gibson, James L., Ivancevich, John M., Donnely, James H., and Konopaske (2009) Organizations: Behavior, Structure, Processes,New York, McGraw Hill.

Guritno, B., \& Waridin. (2015). Pengaruh Persepsi Pegawai Mengenai Perilaku Kepemimpinan, Kepuasan Kerja Dan Motivasi Terhadap Kinerja. JRBI. Vol 1. No 1., 63-74.

Habibi arifin, budaya-organisasi-dan-budayakerja, diakses tanggal 21 Feb 2019.

Hakim. (2008). Analisis Pengaruh Motivasi, Komitmen Organisasi Dan Iklim Organiasasi terhadap pegawai. JRBI Vol 2 No 2, 165-180

Handoko T, Hani (2008), Manajemen Personalia dan Sumber Daya Manusia, Edisi Kedua, BPFE Yogyakarta.
Haryati(2013) "Pengaruh dan Dukungan Organisasi dan budaya kerja Terhadap Kinerja Pegawai pada dinas Kesehatan Kota Cimahi". Universitas Sangga Buana Bandung.

Hasibuan, Malayu, SP (2008), Manajemen Sumber Daya Manusia, PT. Bumi Akasara Jakarta.

Keputusan Menpan no 25/Kep/M.Pan/4/2002 tentang Pedoman Pengembangan Budaya Kerja Aparatur Negara.

Krietner R dan Angelo Kinicki, (2015), Perilaku Organisasi, Salemba Empat Jakarta

Mangkunegara, Anwar, Prabu. (2009). Evaluasi Kinerja SDM, Cetakan 4, Bandung : Refika Aditama

Masrukhin \& Waridin. (2014). Pengaruh Motivasi Kerja, Kepuasan Kerja, Budaya Organisasi Dan Kepemimpinan Terhadap Kinerja Pegawai. . EKOBIS. Vol 7. No 2. , 197-209

Moekijat, Asas-Asas Perilaku

Organisasi,(Bandung : CV. Mandar Maju, 2009).

Nawawi dan Hadari, (2013), Kepemimpinan Yang Efektif, Cetakan Pertama, Gajah Mada, Jakarta.

Nazir, Moh. 2009. Metode Penelitian. Jakarta : Ghalia Putra.

Nitisemito S Alex (2009), Manajemen Personalia, Cetakan Keempat, Ghalia, Jakarta.

Osborn dan Plastrik, Manajemen Sumber Daya Mausia,(Yogyakarta : BPFE, 2012)

Regina Aditya Reza (2010), Pengaruh gaya kepemimpinan, motivasi dan disiplin terhadap kinerja karyawan PT. Sinar Santosa Perkasa Banjarnegara.

Robbins and Judge. 2008. Perilaku Organisasi, Edisi Duabelas. Jakarta : Salemba Empat.

Robbins Coutler, M (2008), Motivasi dan Kepribadian, Terjemahan Nurul Iman, PT. Pustaka Binaman Pressindo, Jakarta. 
Robbins P. Stephen, Coulter Mary alih bahasa oleh Benyamin, (2009), Manajemen, Edisi keenam, Jilid 2, PT. Indeks Jakarta

Robbins, Stephen P. (2011). Perilaku Organisasi Jilid I. Yogyakarta : Aditya Media.

Robertus (2016) "Pengaruh Gaya Kepemimpinan Transformasional, Motivasi Kerja, Dan Budaya Organisasi Terhadap Kinerja Karyawan”. (Studi Pada PT. BPR Arta Utama Pekalongan)Universitas Pekalongan.

Santoso, Singgih (2010), SPSS Statistik Parametrik, PT. Alex Media Komputindo, Kelompok Gramedia Jakarta.

Sedarmayanti. (2009). Good Governance (Kepemerintahan Yang Baik),Bandung : Mandar

Maju Sevilla, Consuelo G. et. al (2008). Research Methods. Rex Printing Company. Quezon City

Siagian, Sondang. P, (2012), Manajemen Sumber Daya Manusia, Cetakan Kesembilan,Bumi Aksara, Jakarta.

Sidanti(2015) "Pengaruh Kepemimpinan dan Budaya Kerja,Terhadap Kinerja Pegawai DPRD Kabupaten Madiun Skripsi", Universitas Cakrawala, Madiun.

Simanjuntak (2011), Sumber Daya Manusia dan Kinerja , Ilham Jaya Bandung.

Sink, R dan Tuttle, J.K. (2008). Evaluasi Kinerja. Jakarta: Indeks Kelompok Gramedia
Sinungan (2011), Filsafat Administrasi, Gunung Agung Jakarta.

Siti Amnuhai. Manajemen Sumber daya Manusia, (Jakarta : Bumi Aksara, 2013)

Taliziduhu Ndraha, Teori Budaya Organisasi, Cetakan Kedua, (Jakarta : PT. Rineka Cipta, 2013),

Triantoro, Safaria. 2014. Kepemimpinan, Edisi Pertama. Yogyakarta : Graha Ilmu.

Triguno. Prasetya, Manajemen Sumber Daya Manusia,(Jakarta : Bumi Aksara, 2011),

Triton PB (2015), Paradigma Baru Manajemen Sumber Daya Manusia, Tugu Yogyakarta.

Wahjosumidjo (2015), Kepemimpinan dan Motivasi, Liberty Yogyakarta

Widari (2016) "Pengaruh kepemimpinan Transformasional dan Dukungan organisasi Terhadap Kinerja Pegawai BKD DIY". Skripsi, Universitas Negeri Yogyakarta.

Winardi. (2012). Motivasi dan Permotivasian Dalam Manajemen. Jakarta : PT Raja Grafindo Persada.

Yeltsin Aprrioke Thomas (2010), Pengaruh fasilitas kerja terhadap kinerja PNS di Kantor Dinas Pendidikan Minahasa Tenggara.

Yulk, Gary. 2010. Kepemimpinan dalam Organisasi. Jakarta: Index. 